\title{
Uterine Rupture with an intact scar- An unexpected catastrophe
}

Prabha lal $^{1}$, kanika chopra ${ }^{2}$, swati dhar ${ }^{3}$, prerna tayal ${ }^{4}$ and kavita ${ }^{5}$

${ }^{1}$ Professor, Department of Obstetrics \& Gynaecology, Lady Hardinge Medical College, New Delhi.

${ }^{2}$ Assistant professor, Department of Obstetrics \& Gynaecology, Lady Hardinge Medical College, New Delhi.

${ }^{3}$ Postgraduate, Department of Obstetrics \& Gynaecology, Lady Hardinge Medical College, New Delhi.

${ }^{4}$ Postgraduate, Department of Obstetrics \& Gynaecology, Lady Hardinge Medical College, New Delhi.

${ }^{5}$ Senior resident, Department of Obstetrics \& Gynaecology, Lady Hardinge Medical College, New Delhi.

Corresponding Author: Kanika Chopra, Assistant professor, Department of Obstetrics \& Gynaecology, Lady Hardinge Medical College, New Delhi, India.

Received date: December 22, 2020; Accepted date: December 28, 2020; Published date: January 08,2021

Citation: lal P., chopra K., dhar S, tayal P. and kavita (2021) Uterine Rupture with an intact scar- An unexpected catastrophe. J of Obstetrics Gynecology and Reproductive Sciences 5(1) DOI: 10.31579/2578-8965/053

Copyright: (c) 2021, Kanika Chopra, This is an open access article distributed under the Creative Commons Attribution License, which permits unrestricted use, distribution, and reproduction in any medium, provided the original work is properly cited.

\section{Abstract}

Rupture of the scarred uterus away from the scar site is an unusual and rare complications in pregnancy. A, second gravida, previous cesarean section patient, at 40 weeks of gestation, not in labor was admitted and planned for elective cesarean in view of breech presentation. Patient suddenly developed acute pain abdomen. On examination, there was tachycardia, uniform tenderness all over her abdomen, with intact uterine contour and fetal heart rate was not localized. At laparotomy, hemoperitoneum and a rent of $2 \times 2 \mathrm{~cm}$ was seen at the anterior wall of upper uterine segment with intact previous cesarean scar. Stillbirth was delivered. Placenta was on the anterior wall of the uterus and delivered completely. Post-operative period was uneventful. Prompt response in cases of scarred uterus to pain abdomen can help in avoiding stillbirth as in our case.

Keywords: anterior uterine wall, intact scar, hemoperitoneum, stillbirth, uterine rupture

\section{Introduction}

Uterine rupture is considered to be one of the most catastrophic events in high risk obstetrics. It is associated with high perinatal and maternal morbidity and mortality. It has an incidence ranging from $0.006 \%$ in developed countries and $0.38 \%$ in developing countries $[1,2]$. Many risk factors have been identified as causal factors with previous cesarean scar being one of them. It is extremely rare to find site of uterine rupture away from previous scar site and here we report a similar case of uterine rupture. Our aim is to highlight the abnormal presentation of rupture uterus, so that catastrophic event can be recognized early with prompt management. This in turn can prevent perinatal and maternal morbidity and mortality.

\section{Case}

A, 18- years- old, G2P1L1A0, was admitted with complaints of completed dates for elective lower segment cesarean section in view of previous lower segment cesarean section with breech presentation after COVID RTPCR report or whenever she goes in labor. Her menstrual history was regular cycles with average flow. She was married for 2 years (second marriage). In her obstetric history she had a male baby of 2.5 years of age from first marriage and lower segment cesarean section was done for breech presentation. She had normal post-operative course in that pregnancy. Past and family history was not significant. On examination, patient was conscious and oriented to time, place and person. Her vitals were pulse rate 88 beats per minute, blood pressure $112 / 76 \mathrm{mmHg}$, respiratory rate 14 per minute and temperature $37.50 \mathrm{~F}$. There was no pallor, icterus, cyanosis, pedal edema. Her cardiovascular and respiratory systems were within normal limits. On per-abdominal examination, on inspection a transverse scar was seen which was healed by primary intention. Uterus was term size with breech presentation. Uterus was relaxed, and was non tense and non-tender with normal tone and contour with no scar tenderness. Liquor was clinically adequate and fetal heart sound was regular, and 144 beats per minute. Estimated fetal weight was $2.8 \mathrm{~kg}$. On per vaginum examination, cervical os was closed, it was uneffaced, firm and posterior, presenting part was high up and pelvis was average gynecoid. Non stress test was done and was found to be reactive. All baseline investigations were sent and her reports were hemoglobin $10.9 \mathrm{gm} \%$, total leucocyte count $11,500 / \mathrm{mm} 3$, platelets $1.2 \mathrm{lack} / \mathrm{mm} 3$. Her liver and kidney function tests were within normal limits. Her last trimester ultrasonography was suggestive of single life fetus, transverse lie, of average gestational age of 30+6 weeks, estimated fetal weight of $1.587 \mathrm{gm} \pm 234 \mathrm{gms}$. Placenta was anterior and not low lying. She was kept on hourly vital charting.

Around 8 hours after her admission, patient complaint of pain abdomen. On examination, she appeared anxious, her vitals were pulse rate 98 beats per minute, normal volume, blood pressure $112 / 70 \mathrm{mmHg}$, respiratory rate 12/min, SPO2 98\%. She was diaphoretic and appeared pale. There was diffuse tenderness all over her abdomen. Uterine contour was normal, there was no scar tenderness, liquor appeared adequate, fetal heart rate was not localized by stethoscope. Urgent ultrasound was done which was suggestive of dead fetus in breech presentation, with moderate free fluid in the peritoneal cavity with internal echoes and heteroechoic dense moving contents suggestive of haemorrhage. Patient was taken for 
laparotomy after arranging adequate blood and informed consents. Intraoperative findings were hemoperitoneum of around $800 \mathrm{cc}$, a rupture of $2 \times 2 \mathrm{~cm}$ was seen in the upper anterior wall of the uterus away from the scar and placenta can be seen through the rent, depicted by blue arrow in figure 1. Previous cesarean scar was intact as marked by green arrow in figure 1 and stillborn baby was delivered via the previous scar. Placenta was delivered complete with membranes. Rent was repaired in two layers. Hemostasis ensured and patient stood the procedure well. Post-operative period was uneventful and patient was discharged with the advice of repeat cesarean section at 34 completed weeks in subsequent pregnancies. The case has been reported after informed consents from the patient.

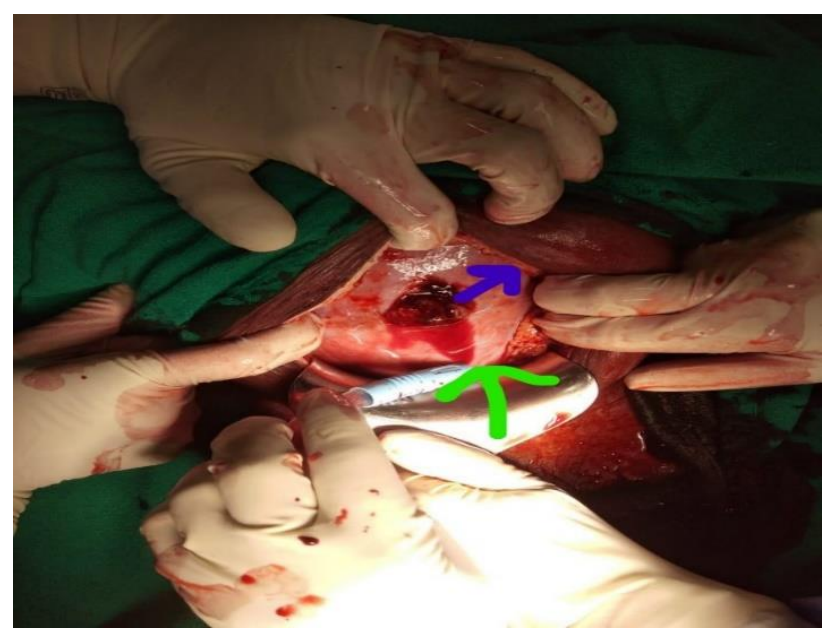

Figure 1. Upper anterior uterine wall rupture (marked by blue arrow) \& intact previous cesarean scar (marked by green arrow).

\section{Discussion}

The risk factors associated with uterine rupture are uterine surgeries, maneuvers like internal version and breech extraction, blunt trauma, grand multipara, oxytocin stimulation, prolonged labour or obstructed labor, macrosomia or abnormal placentation [3].

Usually, uterine rupture is seen in patients with previous cesarean section left for trial of labor as it is presumed to be the weakest point of the uterus.

In unscarred uterus, the risk of uterine rupture is estimated to be 1 in 8000 to 1 in 15,000 deliveries [4].

Few cases have been reported with uterine rupture in areas not anticipated $[5,6]$. The main modality of diagnosis following high clinical suspicion of uterine rupture with unusual clinical presentations is ultrasonography as in our case [7].

In our case, patient had rupture of the upper anterior wall of the uterus with intact previous cesarean scar. One of the first cases of uterine rupture away from the previous intact scar was reported by E Nkwabong et al [5]. In this case, rupture was at the left lateral border of the uterus away from the previous scar. The risk factors in this case were previous cesarean scar and borderline pelvis and patient came in second stage of labour and delivered vaginally. Rupture was detected after the vaginal delivery of the live baby as compared to our case where it happened antepartum and resulted in intrauterine fetal demise.

In, another case, laparotomy was done in view of acute pain abdomen in a G3P1L1A1 with 35 weeks gestation with previous cesarean section and twin pregnancy, not in labour. Intra-operative findings were suggestive of a laceration of $5 \times 6 \mathrm{~cm}$ on anterior wall of upper uterine segment. Previous cesarean scar was intact and both babies were live born. In this case, the risk factors defined were multiparity and multiple gestation leading to over distension [8]. In a case reported by Wang PH et al, similarly rupture occurred in the posterior uterine wall away from scar site, in a patient in spontaneous labour leading to maternal shock and perinatal mortality [6]. No risk factors could be identified in this case as per authors.
Rupture of uterus away from the previous scar site can present with variable signs and symptoms and especially before onset of labor. So, the obstetrician should be aware of such atypical presentation of uterine rupture, so that timely intervention can prevent maternal and perinatal morbidity and mortality. Ideally, biopsy of the rupture site should have been done to determine the underlying pathology that we missed in our case.

\section{References}

1. Hofmeyr GJ, Say L, Gulmezoglu AM. (2005) WHO systematic review of maternal mortality and morbidity: The prevalence of uterine rupture. BJOG; 112(9): 1221-1228.

2. Nyengidiki TK, Augoa DO. (2011) Rupture of the gravid uterus in a tertiary health facility in the Niger delta region of Nigeria: A 5-year review. Niger Med J. 52(4): 230-234.

3. Nkwabong E, Kouam L, Takang W. (2007) Spontaneous uterine rupture during pregnancy. Case report and review of literature. Afr J Reprod Health. 11(2): 107-112.

4. Miller DA, Goodwin TM, Gherman RB et al. (1995) Intrapartum rupture of the unscarred uterus. Am J Obstet Gynecol. 1995; 172(6): 1851-5.

5. Nkwabong E, Bechem E, Nana PN. (2013) Rupture of a scarred uterus without involvement of the previous lower segment uterine scar: A case report. The Internet $J$ of Gynecology \& obstetrics. 17(2).

6. Wang PH, Yuan CC, Chao HT et al. (2000) Posterior uterine wall rupture during labour. Hum Reprod. 15(5): 1198-1199.

7. Has R, Topuz S, Kalelioglu I et al. (2008) Imaging features of postpartum uterine rupture: a case report. Abdom Imaging. 33(1): 101-3.

8. Usharani T, Kavitha B, Geetha L et al. (2015) A case report of unusual site of uterine rupture in pregnancy with scarred uterus. Sch J Med Case Rep. 3(1): 16-18.

\section{Conclusion}

